\title{
BASE NACIONAL COMUM CURRICULAR: ALGUMAS REFLEXÕES A PARTIR DA PEDAGOGIA HISTÓRICO-CRÍTICA ${ }^{1}$
}

\author{
Leonardo Docena Pina ${ }^{2}$ \\ Carolina Nozella Gama ${ }^{3}$
}

\section{Resumo:}

O presente artigo objetiva analisar a versão da Base Nacional Comum Curricular aprovada pelo bloco no poder durante o governo Temer. Para tanto, defende-se a tese de que a BNCC incorpora os interesses de uma fração da classe empresarial, a "direita para o social", e, dessa forma, consolida mais uma etapa do processo de rebaixamento do nível de ensino destinado às camadas populares. Aponta-se as contribuições da teoria pedagógica histórico-crítica como possibilidade de resistência ao esvaziamento curricular expresso na BNCC.

Palavras-chave: base nacional comum curricular; projeto empresarial de formação minimalista; pedagogia histórico-crítica.

\section{BASE NACIONAL COMÚN CURRICULAR: ALGUNAS REFLEXIONES A PARTIR DE LA PEDAGOGÍA HISTÓRICO-CRÍTICA}

\section{Resumen:}

El presente artículo objetiva analizar la versión de la Base Nacional Común Curricular aprobada por el bloque en poder durante el gobierno Temer. Para tanto, se defiende la tesis de que la BNCC incorpora los intereses de una fracción de la clase empresarial, la "derecha para lo social", y, de esa forma, consolida una etapa más del proceso de degradación de la calidad de la enseñanza destinado a las camadas populares. Se apunta las contribuciones de la teoría pedagógica histórico-crítica como posibilidad de resistencia al vaciamiento curricular expreso en la BNCC.

Palabras clave: base nacional común curricular; proyecto empresarial de formación minimalista; pedagogía histórico-crítica.

\section{NATIONAL CURRICULUM COMMON BASE: SOME REFLECTIONS FROM THE HISTORICAL-CRITICAL PEDAGOGY}

\section{Abstract:}

This present article aims at analyzing the version of the National Curriculum Common Base approved by the staff in charge during Temer's government. Therefore, it defends the thesis that BNCC incorporates the interests of a fractions of the business class, the "right-wing for the social", thus, it consolidates one more step of the process of debasement of the learning level destined to the lower classes. It shows the contributions of the historical-critical pedagogical theory as a possibility of resistance to the curriculum emptying expressed in the BNCC.

Key-words: National curriculum common base; business project of minimalist formation; historical-critical pedagogy.

\section{Introdução}

\footnotetext{
${ }^{1}$ Artigo recebido em 17/01/20. 1a Avaliação em 21/03/20. 2ª Avaliação em 20/04/20. 3a Avaliação em 21/04. Aprovado em 22/04/20. Publicado em 22/05/20. DOI: https://doi.org/10.22409/tn.v18i36.40400

${ }^{2}$ Professor da Universidade Federal de Juiz de Fora (UFJF), Minas Gerais - Brasil. Doutor em Educação pela UFJF - Minas Gerais - Brasil. E-mail: leodocena@yahoo.com.br ORCID: 0000-0002-9603-0575.

${ }_{3}$ Professora da Universidade Federal de Alagoas (UFAL) - Brasil. Doutora em Educação pela Universidade Federal da Bahia (UFBA) - Brasil. E-mail: carolina.gama@cedu.ufal.br. ORCID: 00000002-4379-6366.
} 
O presente texto é fruto da mesa BNCC: algumas reflexões a partir da pedagogia histórico-crítica, realizada durante o Congresso "Pedagogia HistóricoCrítica: em defesa da Escola Pública e Democrática em tempos de Projetos de “Escolas sem Partidos"', que ocorreu de 11 a 13 de julho de 2018, na F.C.T./UNESP de Presidente Prudente-S.P. Fundamentando-se na pedagogia histórico-crítica objetiva analisar a versão da Base Nacional Comum Curricular (BNCC) aprovada pelo bloco no poder durante o governo Temer (BRASIL, 2017) ${ }^{4}$. Busca-se dar continuidade às reflexões desenvolvidas por Marsiglia et. al (2017) e por Marsiglia, Machado e Pina (2018) no sentido de evidenciar limites da política curricular em questão no que diz respeito à formação das futuras gerações. Para tanto, o texto defende a tese de que a BNCC incorpora os interesses de uma fração da classe empresarial, a "direita para o social" (DPS), e, dessa forma, consolida mais uma etapa do processo de rebaixamento do nível de ensino destinado às camadas populares.

As reflexões são apresentadas em três partes, além desta introdução. $\mathrm{Na}$ primeira, intitulada "A 'direita para o social' e seu projeto de Educação Básica", evidenciamos a organização política da DPS para consolidar, na política educacional, sua perspectiva de escola pública. Na segunda parte, intitulada "Fundamentos pedagógicos da BNCC: uma expressão do projeto empresarial de formação minimalista", evidenciamos que, ao contemplar os principais fundamentos almejados pela DPS, a BNCC acaba por intensificar a apropriação privada do conhecimento sistematizado. Por fim, nas considerações finais, pontuamos que a aprovação da BNCC compõe o conjunto de iniciativas aprovadas pelo bloco no poder para avançar com o processo de retirada de direitos dos trabalhadores. Além disso, indicamos que a pedagogia histórico-crítica é a teoria pedagógica que se opõe radicalmente ao esvaziamento curricular promovido pela BNCC.

\footnotetext{
${ }^{4}$ No dia 15 de dezembro de 2017 foi aprovado o Parecer CNE/CP no 15/2017, referente à Base Nacional Comum Curricular (BNCC). Compõe os anexos desse documento, o texto da BNCC referente à Educação Infantil e ao Ensino Fundamental, analisado no presente artigo. No dia 22 de dezembro de 2017 foi publicada a Resolução CNE/CP no 2, que institui e orienta a implantação da Base Nacional Comum Curricular.
} 


\section{A "direita para o social - DPS" e seu projeto de Educação Básica}

Martins (2009) constatou que, a partir dos anos de 1990, ocorreu uma atualização das iniciativas empresariais nas relações de hegemonia. $O$ autor comprova que um grupo de empresários aprimorou suas intervenções na "questão social" e na influência das políticas, dando origem ao que denominou de "direita para o social" (MARTINS, 2009). Composta por empresários dos setores financeiro, bancário e de serviços, a DPS passou a difundir a "responsabilidade social" como ideologia para organizar a própria classe e subordinar o conjunto da sociedade à sua concepção de mundo.

Dois organismos empresariais assumiram, ainda nos anos 1990, a função de orientar a própria classe para o exercício de uma intervenção de novo tipo nas relações de hegemonia, a fim de garantir o avanço das políticas neoliberais. São eles: o Grupo de Institutos Fundações e Empresas (GIFE) e o Instituto Ethos de Empresas e Responsabilidade Social (IE).

Alinhados ao mesmo objetivo, GIFE e IE propuseram ações em diferentes campos da "questão social", dentre eles, a educação escolar. Na perspectiva desses organismos, os empresários deveriam desenvolver iniciativas voltadas ao aumento da "qualidade" da educação pública no Brasil. A DPS considera as avaliações externas como o parâmetro mais adequado para mensurar a "taxa de retorno" dos investimentos, por isso, opera com uma perspectiva restrita de qualidade, tal como ocorre com o Índice de Desenvolvimento da Educação Básica (IDEB).

Conforme comprova Pina (2016), as proposições do GIFE e do IE para a Educação Básica envolvem o incentivo à noção de parceria, ao gerencialismo e à formação de novos organizadores e difusores dos preceitos empresariais. Esses organismos já defendiam, na década de 1990, que as iniciativas "socialmente responsáveis" deveriam promover alterações na política educacional. Nessa linha, o IE afirmou: "[...] os empresários e empresárias brasileiros precisam assumir seu mandato na definição de políticas públicas do setor educacional" (IE, 1999, p. 59). Seguindo essa orientação, os institutos e fundações empresariais que foram sendo criados, a partir dos anos 2000, para multiplicar os esforços em torno da ideologia da responsabilidade social passaram a considerar a contrarreforma na educação escolar como uma prioridade. 
A análise de produções da DPS revela a existência de um projeto empresarial para a Educação Básica pública, cujos fundamentos podem ser sintetizados em quatro pilares que se relacionam entre si: privatização, divisão técnica do trabalho, responsabilização pelo desempenho dos estudantes nas avaliações externas e patamar minimalista de formação escolar (PINA, 2016).

\subsection{Privatização e divisão técnica do trabalho}

A privatização foi apresentada, no Plano Diretor da Reforma do Aparelho de Estado (BRASIL, 1995), como elemento chave no processo de contrarreforma do Estado. Argumentava-se que as atividades não vinculadas ao "poder de Estado" deveriam ser transferidas da aparelhagem estatal para reduzir os gastos públicos.

Assim, as atividades lucrativas, que envolvem produção de bens e serviços, deveriam ser transferidas para o grupo social supostamente capaz de executá-las com mais eficiência: os empresários. Por outro lado, algumas atividades que transcendem o "poder de Estado" não poderiam ser privatizadas. O argumento era o de que, nas atividades sociais e científicas, os empresários não conseguiriam gerar toda receita necessária com a venda de serviços e, dessa forma, não poderiam assumi-las. Mas, dada a suposta ineficiência do aparelho de Estado para gerir essas atividades, a alternativa encontrada foi a defesa de uma privatização de novo tipo, denominada de "publicização" (BRASIL, 1995). Por meio desta, as atividades sociais e científicas do Aparelho de Estado seriam repassadas para as "organizações públicas não estatais" ou "organismos sociais", que receberiam verbas públicas para administrar "[...] um tipo de serviço por definição subsidiado" (BRASIL, 1995, p. 43). Argumentava-se que isso tornaria o aparelho de Estado mais eficiente.

Traduzindo tais fundamentos para a Educação Básica, a DPS recorre à noção de "parceria" a fim de impulsionar a privatização nas escolas e redes públicas de ensino. Uma de suas proposições envolve a defesa do que Adrião et. al. (2018) denominam de "privatização do currículo", isto é, processos pelos quais o empresariado determina, para escolas, redes ou sistemas públicos, os desenhos curriculares, seja por meio de assessorias, de oferta de tecnologias educacionais e demais insumos curriculares, seja ainda por meio dos Sistemas Privados de Ensino. Trata-se, segundo os autores, da privatização dos processos pedagógicos strictu sensu, envolvendo as relações entre professores, estudantes e conhecimento. Nessa 
linha, encontram-se as proposições da Fundação Lemann (FL) sobre a "sala de aula estruturada" (Louzano et. al., 2008; Becskeházy e Louzano, [201-].).

Pina (2016) evidencia que a defesa pela FL dos Sistemas Privados de Ensino se articula às proposições empresariais - como as da Fundação Itaú Social (FIS) que visam moldar e controlar as atividades desenvolvidas na escola por meio da divisão técnica do trabalho.

Na perspectiva da FL, a moldagem da atividade docente deveria ser obtida pela aquisição de "sistemas estruturados de ensino" que retiram do professor a atividade de planejamento. Recorrendo a uma de suas intelectuais, a FL defende que os docentes não deveriam planejar suas aulas, pois, assim, sua "energia" pode ser direcionada apenas para a execução do planejamento e o atendimento das "necessidades de aprendizagem" dos estudantes, argumenta Melo (2010).

Não obstante, na perspectiva empresarial, a execução do planejamento a ser aplicado pelos professores precisa ser controlada. Com efeito, tanto a FIS quanto a FL propõem a redefinição do papel do diretor, de representante da comunidade escolar para representante da classe empresarial no interior da escola. Busca-se convertê-lo em um gerente responsável pela aplicação do projeto empresarial no interior das escolas públicas. É nesse sentido que surge a defesa pela FIS da "tutoria pedagógica" (FIS, [201-]; GALL e GUEDES, 2012). Essa proposição visa assegurar que os "tutores" atuem como supervisores para exercer comando e controle do trabalho dos professores. Assim, fiscalizam as salas de aula auxiliando os diretores a consolidar a cultura de auditoria dirigida pela classe empresarial nas escolas públicas.

Conforme comprova Pina (2016), a divisão técnica do trabalho defendida pela DPS atualiza a histórica divisão ordenada em dois níveis. No mais alto, estariam os formuladores pedagógicos, responsáveis por conceber atividades administrativas julgadas como mais eficientes e eficazes. A estes caberia, dentre outros, elaborar diretrizes curriculares e instrumentos de avaliação da aprendizagem, além de definir os parâmetros de aferição da eficiência das unidades escolares. No plano mais elementar, o dos executores, estariam os professores, diretores e coordenadores pedagógicos, responsáveis por seguir as formulações produzidas pelo núcleo estratégico que compõe o primeiro nível mencionado. Vale o alerta de que, embora se mantenha no plano dos executores, a "equipe de gestão escolar" teria uma função 
estratégica, qual seja, a de garantir a aplicação dos princípios gerenciais na organização e funcionamento das escolas.

Dessa forma, a DPS visa racionalizar o trabalho educativo tal como propunha a pedagogia tecnicista analisada por Saviani (2006). O autor explica que o tecnicismo buscou objetivar e operacionalizar o trabalho educativo da mesma forma como a burguesia incidiu no trabalho fabril. Ou seja, no artesanato, os instrumentos de trabalho eram dispostos em função do trabalhador e este dispunha deles segundo seus desígnios, porém, na produção fabril, essa relação foi invertida, pois, nesse caso, o trabalhador teve que "[...] se adaptar ao processo de trabalho, já que este foi objetivado e organizado na forma parcelada" (SAVIANI, 2006, p. 12). Seguindo essa mesma linha, a pedagogia tecnicista buscou planejar a educação escolar para dotála de uma organização racional, supostamente capaz de minimizar as interferências subjetivas que poderiam pôr em risco a sua eficiência. Assim explica Saviani (2006, p.13):

[...] na pedagogia tecnicista, o elemento principal passa a ser a organização racional dos meios, ocupando o professor e o aluno posição secundária, relegados que são à condição de executores de um processo cuja concepção, planejamento, coordenação e controle ficam a cargo de especialistas supostamente habilitados, neutros, objetivos, imparciais. A organização do processo converte-se na garantia da eficiência, compensando e corrigindo as deficiências do professor e maximizando os efeitos de sua intervenção.

Recorrendo aos fundamentos dessa perspectiva pedagógica e atualizando-a na forma de neotecnicismo (SAVIANI, 2011), a DPS busca assegurar a apropriação privada do conhecimento científico, filosófico e artístico pela redução do trabalho educativo a treinamento de "competências" e habilidades consideradas funcionais à preservação das relações sociais de dominação, tal como evidenciaremos no último tópico desta seção.

\subsection{Responsabilização pelo desempenho dos estudantes nas avaliações externas}

Outra proposição apresentada pela DPS para melhorar a "qualidade" da educação pública brasileira é a responsabilização educacional. Os fundamentos da proposta também estão presentes no documento que orientou a implantação do neoliberalismo no país (BRASIL, 1995). Argumentava-se que a eficiência do setor público só poderia ser alcançada com a adoção de mecanismos de controle dos 
resultados, a exemplo da noção de accountability, que, segundo Afonso (2012), integra três pilares: avaliação, prestação de contas e responsabilização.

Mais recentes no Brasil, os fundamentos do accountability na educação escolar remontam ao ano de 1983, quando foi lançado o relatório final da comissão nacional criada pelo governo Ronald Reagan - denominado "Uma Nação em Risco" - para estudar a situação da educação escolar nos Estados Unidos. Desde então, intelectuais defensores da contrarreforma passaram a considerá-lo um instrumento capaz de focar o desempenho dos estudantes ao "premiar" ou punir os professores de acordo com seu suposto desempenho, medido pelo rendimento dos estudantes nas avaliações externas. Essa é a visão da FIS e da FL.

As entidades criticam o fato de a remuneração dos professores, na maioria das redes de ensino, ser única para todos, oferecendo uma base salarial que varia em função de dois critérios, tempo de serviço e titulações obtidas, ao passo que, em outras profissões, a incidência de remuneração variável com base nos resultados e produtividade é prática comum. Diante disso, defendem que a meritocracia gera impactos positivos no trabalho dos professores, como defende a FL, por meio de uma de suas intelectuais:

\begin{abstract}
Através de um bônus por desempenho para professores, espera-se alinhar os interesses do aluno aos dos professores e assim motivar o professor a aumentar seu esforço dentro de sala de aula, contribuir para a profissionalização do magistério, estimular professores a investirem no seu próprio desenvolvimento profissional, assim como atrair professores mais bem qualificados para a profissão. Ou seja, não só melhorar a produtividade de quem já está na profissão, mas aumentar a qualidade da força de trabalho docente como um todo, atraindo e retendo professores cujos alunos obtêm alto desempenho (PONTUAL, 2008, p.4-5).
\end{abstract}

Para a FIS, o oferecimento de "bônus" com base no desempenho dos estudantes nas avaliações externas seria insuficiente para melhorar a "qualidade" da educação, dada sua incapacidade de "incentivar" todos os professores. O entendimento é o de que apenas os mais "esforçados" seriam motivados por essa iniciativa. Para os outros, que não alcançam "metas de aprendizagem", seria necessário outro tipo de "incentivo", qual seja, as punições, incluindo, até mesmo, a demissão, de modo que o medo possa alinhar o interesse do professor aos supostos interesses dos alunos. Daí a defesa pela FIS de um sistema de avaliação que implique na adoção de sanções e incentivos (GALL e GUEDES, 2012). 
Os organismos empresariais consideram que as avaliações externas, às quais são submetidos os estudantes, revelam o desempenho dos professores. Assim, entendem que a definição do IDEB, que instituiu as avaliações externas como parâmetro de qualidade da educação pública, abriu espaço para responsabilizar os professores em função das metas estabelecidas. A estratégia ideológica difunde que os docentes são os principais responsáveis pelo baixo desempenho dos alunos nos exames. Para tanto, desconsideram os fatores extraescolares que interferem no aprendizado e, ao mesmo tempo, desqualificam os professores. Em seguida, são apresentados, como solução, os fundamentos da lógica empresarial, tais como: (a) perda de estabilidade, (b) combinação entre incentivo e sanções, (c) carreira meritocrática. Assim, difunde-se o consenso em torno da necessidade de aprofundar a lógica do mercado na educação pública.

Apesar do que sugerem as formulações da DPS, os professores, coordenadores pedagógicos e diretores não são os únicos responsáveis pelo aprendizado dos estudantes. $A$ isso equivale dizer que esses profissionais têm suas responsabilidades na escolarização dos discentes, mas são inúmeros os fatores que impactam nesse processo. A ideia de que um "excelente professor", mesmo em condições adversas, faz toda a diferença no aprendizado das crianças se constitui como uma das bases que compõem arsenal ideológico da DPS em prol da contrarreforma na educação escolar. Na mesma linha, encontra-se o entendimento de que as avaliações externas e os índices dela decorrentes, como é o caso do IDEB, expressam o rendimento da atividade desenvolvida pelos professores. A rigor, essas avaliações indicam o rendimento dos alunos, posicionamento também defendido por Ravitch (2011). A autora explica que um dos problemas centrais ao se utilizar as avaliações externas como critério para tomar decisões importantes sobre a escola e a vida das pessoas que atuam nessa instituição consiste no fato de que "[...] os testes padronizados não são instrumentos precisos" (RAVITCH, 2011, p. 174). Diz ela que até mesmo os especialistas em testagem alertam que os escores das avaliações deveriam ser usados apenas para o propósito para o qual foram projetados, qual seja, o de avaliar os alunos e não o professor.

Embora a responsabilização seja recomendada atualmente pela DPS como ação eficaz para melhorar a "qualidade" da educação, não se pode perder de vista que a implantação da "gestão por resultados" no sistema educacional tem menos a 
ver com questões propriamente educativas e mais com a busca do gerencialismo, uma vez que os resultados dos alunos nas avaliações em larga escala não são fim, mas meio para quebrar a isonomia salarial e instituir novas formas de gestão de professores (SHIROMA e EVANGELISTA, 2011).

\subsection{Patamar minimalista de formação escolar}

Os lemas empresariais da "promoção da aprendizagem", da melhoria da "qualidade", dentre outros, tendem a ser vistos como representantes de uma perspectiva que atende aos interesses dos alunos da escola pública. Todavia, a privatização, a divisão técnica do trabalho e a responsabilização são proposições que incidem nas atividades desenvolvidas na escola para intensificar a apropriação privada do saber sistematizado.

Considerando que, na sociedade moderna, o conhecimento sistematizado se constitui como força produtiva e instrumento potencial para compreensão das relações sociais, a classe empresarial vem estabelecendo mecanismos para controlar sua apropriação, concebendo-o como propriedade exclusiva de sua classe. Assim, historicamente, o trabalho educativo vem sendo orientado por concepções que visam distanciar a educação escolar das necessidades humanas reais, sugerindo que o domínio amplo do saber sistematizado seria supérfluo aos trabalhadores em função de suas necessidades imediatas de vida.

A estratégia ideológica utilizada pela DPS para aprofundar essa tendência de apropriação privada dos meios de produção passa pela defesa de lemas que sugerem uma transformação da escola para melhor, como se as mudanças propostas pela classe empresarial fossem capazes de atender aos interesses dos estudantes que compõem a fração mais pauperizada dos trabalhadores. Dessa forma, se obscurece o fato de que o desenvolvimento de suas proposições na realidade brasileira agrava ainda mais o rebaixamento do ensino nas escolas públicas.

Conforme comprova Pina (2016), a análise da concepção pedagógica que sustenta as iniciativas da DPS revela um esvaziamento da formação escolar assentado na pedagogia das competências, na metodologia dos projetos, na noção de aprendizagem significativa e, dentre outros, no estreitamento curricular decorrente da ênfase em Língua Portuguesa e Matemática. 
Pode-se dizer que a DPS visa ao desenvolvimento das chamadas competências consideradas úteis ao padrão dominante de sociabilidade. É a esse objetivo que se ligam as iniciativas de privatização, divisão técnica do trabalho e responsabilização, pois, na visão empresarial, tais fundamentos devem garantir que o professor "ensine bem" segundo o parâmetro de qualidade pré-definido: deve-se aumentar o rendimento dos alunos nos testes em larga escala por meio das pedagogias do "aprender a aprender", o que significa distanciar o trabalho educativo das máximas possibilidades de desenvolvimento dos estudantes, de modo a oferecer, aos futuros trabalhadores, uma escolarização restrita ao uso funcional dos rudimentos do saber. Eis o que denominamos de patamar minimalista de formação.

Interessada em garantir a base para o aprofundamento de seu projeto de escola pública, a DPS criou, em 2013, o Movimento pela Base Nacional Comum (MBNC), organismo da classe empresarial que reúne inúmeros de seus aparelhos privados de hegemonia, tais como: Instituto Unibanco, Instituto Ayrton Senna, Fundação Lemann e Todos pela Educação (TPE).

A função específica do MBNC nas relações de poder é a de garantir o alinhamento da BNCC ao projeto empresarial de Educação Básica. Para tanto, o organismo sintetiza a concepção de BNCC dos organismos empresariais, recorrendo aos fundamentos defendidos pela FL e pelo TPE.

Na perspectiva da FL, a definição de uma base nacional comum potencializa políticas e ações que, juntas, podem reduzir as desigualdades educacionais. A implementação da base seria, na visão da entidade, mais uma ação necessária para alcançarmos uma educação de "qualidade". O argumento defendido é o de que "Todos os alunos e alunas, independentemente da região onde vivem ou de sua condição socioeconômica, têm o direito de aprender. É isso que a Base Nacional Comum Curricular (BNCC) busca garantir" (FL, 2018, online).

O TPE também se alinha a esse entendimento ao defender uma de suas bandeiras: a definição dos "direitos de aprendizagem". O organismo explica que o país já conta com o IDEB e com metas definidas para as redes e as escolas, contudo, "[...] ainda não foram definidos os direitos de aprendizagem, as expectativas dos alunos brasileiros por série ou por ciclo. Ou seja, os exames acabam cobrando algo que nunca foi estabelecido pelo Estado nem alinhado previamente com as escolas" (TPE, 
2018, online). Daí o entendimento da DPS de que há urgência para definir os objetivos pedagógicos a serem seguidos pelas redes, escolas e professores.

Essa preocupação dos organismos empresariais com a definição dos "direitos de aprendizagem" se vincula à necessidade de padronizar os objetivos pedagógicos a serem cobrados nas avaliações externas, de modo a viabilizar, assim, o estabelecimento de um maior controle sobre o trabalho educativo. Como não há um padrão definido nacionalmente sobre o qual todas escolas públicas podem ser cobradas da mesma forma, a DPS propõe o preenchimento dessa lacuna com a BNCC.

Diante das reflexões apresentadas, torna-se evidente que, para a DPS, a aprovação de uma BNCC articulada ao seu projeto de Educação Básica se configura com um desafio a ser enfrentado pela própria classe. Portanto, questionamos: será que a BNCC aprovada pelo bloco no poder incorporou os interesses fundamentais da DPS? O documento aprovado se alinha aos fundamentos do projeto de Educação Básica da DPS? Essas questões podem ser respondidas ao analisarmos os fundamentos pedagógicos da BNCC.

\section{Fundamentos pedagógicos da BNCC: uma expressão do projeto empresarial de formação minimalista}

As propagandas veiculadas pelo governo federal acerca da BNCC afirmam: "Todos os estudantes, de norte a sul do país, de escolas públicas ou particulares, terão os mesmos direitos de aprendizagem", e ainda "Se a base da educação é a mesma, as oportunidades também serão" ${ }^{2}$. Porém, o contexto da economia política nacional aponta no sentido oposto, uma vez que estão sendo impetrados sérios ataques aos direitos sociais, como pode ser visto na aprovação da Emenda Constitucional 95, que congela os investimentos públicos em áreas sociais por 20 anos; Reforma trabalhista; Reforma da previdência; Reforma do Ensino Médio; Projeto escola sem partido; Política Nacional de Avaliação e Exames da Educação Básica; Leilões do pré-sal, bem como o avanço das privatizações.

\footnotetext{
${ }^{5}$ Disponível em: https://www.youtube.com/watch?v=Fbz-cpct1W4, acesso em 11/11/2018 às 11:16h.
} 
Ora, é sabido que uma educação de qualidade custa caro, e que há décadas os movimentos sociais e as entidades educacionais defendem a ampliação dos recursos do Produto Interno Bruto $(\mathrm{PIB})$ para educação como necessários à melhoria da qualidade da mesma, pois o que se investe atualmente é insuficiente para resolver um déficit histórico das políticas sociais, em especial as voltadas à educação. Sem isto, é ludibriosa a promessa de que "Todos os estudantes, de norte a sul do país, de escolas públicas ou particulares, terão os mesmos direitos de aprendizagem". Afinal, isto não se faz sem condições adequadas de formação, trabalho, carreira e salário dos professores e demais profissionais do magistério, nem mesmo com escolas sucateadas e número de vagas insuficientes para atender à demanda por matrícula, em especial, na educação infantil, ensino médio e ensino superior.

A análise dos fundamentos pedagógicos da BNCC permite-nos desvendar os reais objetivos deste documento, que oficializa, no campo do currículo, o projeto empresarial de formação minimalista voltado às camadas populares. Conforme pode ser visto no excerto seguinte, o foco da formação centra-se no desenvolvimento de competências e habilidades. Tal orientação é justificada, predominantemente, por ser esta a abordagem exigida nas avaliações externas, a exemplo do Programa Internacional de Avaliação de Alunos (PISA), coordenado pela Organização para a Cooperação e Desenvolvimento Econômico (OCDE):

[...] desde as décadas finais do século $X X$ e ao longo deste início do século XXI, o foco no desenvolvimento de competências tem orientado a maioria dos Estados e Municípios brasileiros e diferentes países na construção de seus currículos. E esse também o enfoque adotado nas avaliações internacionais da Organização para a Cooperação e Desenvolvimento Econômico (OCDE), que coordena o Programa Internacional de Avaliação de Alunos (Pisa, na sigla em inglês), e da Organização das Nações Unidas para a Educação, a Ciência e a Cultura (Unesco, na sigla em inglês), que instituiu o Laboratório Latinoamericano de Avaliação da Qualidade da Educação para a América Latina (BRASIL, 2017, p.13, grifos nossos).

Dando continuidade à análise do texto aprovado, observa-se que o emprego do termo "desenvolvimento" ao longo do documento reforça a concepção de formação pautada nas competências. O uso do termo Desenvolvimento de competências ocorre dez vezes, seguido pelo termo Desenvolvimento de habilidades, que aparece nove vezes. O termo Desenvolvimento humano [global] ocorre duas vezes, seguido pelos termos Desenvolvimento pleno [de todos os estudantes nas suas singularidades e diversidades] e Desenvolvimento pleno [das crianças], que são empregados uma vez 
cada um. Como já apontaram os estudos de Marsiglia et. al. (2017), há uma ausência da referência em relação aos conteúdos e conhecimentos sistematizados a serem apropriados no processo formativo, e uma ênfase no "saber fazer" voltado às necessidades imediatas da vida cotidiana e do mundo do trabalho. $\mathrm{O}$ trecho trazido na sequência elucida tal perspectiva formativa:

Ao adotar esse enfoque, a BNCC indica que as decisões pedagógicas devem estar orientadas para o desenvolvimento de competências. Por meio da indicação clara do que os alunos devem "saber" (considerando a constituição de conhecimentos, habilidades, atitudes e valores) e, sobretudo, do que devem "saber fazer" (considerando a mobilização desses conhecimentos, habilidades, atitudes e valores para resolver demandas complexas da vida cotidiana, do pleno exercício da cidadania e do mundo do trabalho), a explicitação das competências oferece referências para o fortalecimento de ações que assegurem as aprendizagens essenciais definidas na BNCC. (BRASIL, 2017, p.13, grifos nossos).

Nessa perspectiva, a formação volta-se à adaptação, flexibilização e ao trabalho simples e precário, conforme apontaram Motta e Frigotto (2017) em seus estudos acerca da contrarreforma do ensino médio. O rebaixamento do currículo da Educação Básica também evidencia-se na concepção de "educação integral" adotada, que se alinha à defendida pela FIS (2013a; 2013b; 2013c). Na perspectiva dessa entidade, sua visão de "educação integral" anuncia "[...] o surgimento de uma nova escola, de novos professores e orientadores da aprendizagem para os alunos do século XXI" (FIS, 2013c, p. 103). A proposição empresarial em questão transcende o mero aumento da jornada escolar, pois representa a adoção de concepções e ações pedagógicas - um conjunto de estratégias - supostamente aptas para oferecer uma "formação mais ampla" aos estudantes. Assim afirma o organismo: "A educação integral pressupõe um conjunto de estratégias para a formação completa do ser humano, amplia a concepção da educação proporcionada pela escola e pela família, e abre espaço para o envolvimento e a responsabilização de toda a sociedade em relação às novas gerações" (FIS, 2013a, p. 7).

Conforme análise realizada por Pina (2016), a concepção da DPS de "educação integral" recorre a uma estratégia ideológica bastante refinada: por um lado, argumenta estar ampliando as possibilidades de apropriação do conhecimento sistematizado, seja pelo oferecimento de "formação mais ampla" e/ou "metodologias inovadoras", seja pelo aumento da carga horária destinada à formação dos 
estudantes, dentre outros; todavia, por outro lado, assegura que sejam adotados mecanismos que garantam o rebaixamento do nível de escolarização.

Pode-se dizer que o mesmo ocorre na BNCC: apesar de promover o esvaziamento curricular, o documento apresenta o rebaixamento do ensino com uma roupagem sedutora, qual seja, a de uma formação articulada a um suposto "desenvolvimento global" ou, ainda, "desenvolvimento pleno" dos estudantes:

[...] a BNCC afirma, de maneira explícita, o seu compromisso com a educação integral. Reconhece, assim, que a Educação Básica deve visar à formação e ao desenvolvimento humano global, o que implica compreender a complexidade e a não linearidade desse desenvolvimento, rompendo com visões reducionistas que privilegiam ou a dimensão intelectual (cognitiva) ou a dimensão afetiva. Significa, ainda, assumir uma visão plural, singular e integral da criança, do adolescente, do jovem e do adulto - considerando-os como sujeitos de aprendizagem - e promover uma educação voltada ao seu acolhimento, reconhecimento e desenvolvimento pleno, nas suas singularidades e diversidades (BRASIL, 2017, p. 14, grifo no original).

Além de articular a formação escolar a processos educativos que promoveriam um suposto desenvolvimento pleno dos estudantes, a concepção de educação integral com a qual trabalha a BNCC teria, ainda, outra "virtude": a de se comprometer com uma formação que reconhece os interesses e necessidades dos discentes e, ao mesmo tempo, atende as supostas demandas do "novo mundo". Vejamos como essa questão se expressa no documento:

Independentemente da duração da jornada escolar, o conceito de educação integral com o qual a BNCC está comprometida se refere à construção intencional de processos educativos que promovam aprendizagens sintonizadas com as necessidades, as possibilidades e os interesses dos estudantes e, também, com os desafios da sociedade contemporânea (BRASIL, 2017, p. 14).

Mas, para a BNCC, quais seriam os desafios da sociedade contemporânea no que diz respeito à formação escolar? Longe de articular a escola à transmissão das formas mais desenvolvidas do conhecimento científico, filosófico e artístico produzidos pela humanidade, a concepção de educação integral da BNCC, assim como a defendida pela DPS, parte do entendimento de que as transformações ocorridas no capitalismo contemporâneo impõem às escolas públicas o desafio de formar as capacidades adaptativas dos sujeitos, de modo que estes se adequem constantemente aos ditames dos novos padrões de produção. Reside aí uma das razões que levam a BNCC a optar pelo esvaziamento da formação escolar, uma vez que adota a "pedagogia das competências" (RAMOS, 2001) sob o lema de que é 
necessário preparar os indivíduos para a adaptação permanente ao meio instável da contemporaneidade. Assim explica o documento:

No novo cenário mundial, reconhecer-se em seu contexto histórico e cultural, comunicar-se, ser criativo, analítico-crítico, participativo, aberto ao novo, colaborativo, resiliente, produtivo e responsável requer muito mais do que o acúmulo de informações. Requer o desenvolvimento de competências para aprender a aprender, saber lidar com a informação cada vez mais disponível, atuar com discernimento e responsabilidade nos contextos das culturas digitais, aplicar conhecimentos para resolver problemas, ter autonomia para tomar decisões, ser proativo para identificar os dados de uma situação e buscar soluções, conviver e aprender com as diferenças e as diversidades (BRASIL, 2017, p.14, grifos nossos).

Portanto, trata-se de uma defesa explícita da formação de um sujeito resiliente, produtivo, colaborativo, aberto ao novo, em suma, de alguém capaz de "aprender a aprender". Predomina-se o pragmatismo e o utilitarismo, que se desdobram no desenvolvimento de competências necessárias para a resolução de demandas da vida cotidiana e do mundo do trabalho, no incentivo ao autocuidado, às relações interpessoais de boa convivência, à flexibilidade e à resiliência. Em outras palavras, valores próprios da capacitação de empresas vão dando o tom do documento que orienta a educação nacional.

Se desvelarmos o discurso das diferenças e diversidades como forma de mascarar e justificar as desigualdades econômicas, compreenderemos que a BNCC pauta-se no subjugo do conhecimento sistematizado pelo saber cotidiano, bem como na defesa de uma formação voltada à adaptação e ao apaziguamento quando, por exemplo, se aponta a necessidade de um sujeito proativo que saiba lidar com as diferenças e diversidade. Trata-se de formar sujeitos capazes de aceitar com passividade as desigualdades de classe, que restringem o acesso à riqueza produzida pela humanidade, o que inclui o conhecimento sistematizado.

Ao examinarmos as "competências gerais da educação básica", expostas nas páginas nove e dez do documento, observamos o emprego dos seguintes verbos: Valorizar e Utilizar (três vezes cada); Exercitar (duas vezes); Recorrer; fruir; compreender; criar; argumentar; conhecer-se; apreciar-se; cuidar e agir (uma vez cada). E quanto à conhecer; relacionar; analisar; sintetizar; generalizar; abstrair? Essas são funções necessárias à formação dos comportamentos complexos, viabilizados pelo desenvolvimento das funções psíquicas superiores, que perpassam pela socialização dos conhecimentos sistematizados ao longo da história pela 
humanidade (MARTINS, 2013). Os estudos desenvolvidos por Martins (2013) apontam o papel da educação escolar no desenvolvimento do psiquismo complexo, o que se dá pela superação dos conceitos cotidianos, que predominam nas competências elencadas para toda a etapa Educação Básica na BNCC, na direção da produção dos conceitos científicos, conforme preconizam a pedagogia histórico-crítica e a psicologia histórico cultural.

A internalização de signos, a formação de conceitos, a superioridade dos conceitos científicos em relação aos conceitos cotidianos etc., sobejamente defendidas pela psicologia histórico-cultural, encontra 0 mais absoluto eco nessa corrente de pensamento pedagógico, para a qual a formação da consciência não se aparta da construção do conhecimento, tanto quanto a qualidade dessa formação não se isenta da natureza do saber sistematizado (MARTINS, 2013, p.12).

No que tange à composição do currículo do Ensino Fundamental, chama a atenção a obrigatoriedade das disciplinas de Língua Inglesa e do Ensino Religioso. Esta última passa a compor a área de Ciências Humanas, ocupando lugar considerável no documento, uma vez que é abordada em vinte e quatro páginas, estando apenas seis páginas atrás da área completa de Ciências da Natureza (abordada em trinta páginas), bem como apenas doze páginas atrás da disciplina de História (abordada em trinta e seis páginas). Isso revela um avanço do conservadorismo no currículo oficial, além de uma certa dependência, para não dizer subordinação ao imperialismo norte americano, com a adoção do idioma inglês como segunda língua oficial.

Malanchen (2014), ao analisar os documentos oficiais do Ministério da Educação do Brasil entre os anos de 2006 a 2012 no bojo de continuidade das reformas curriculares iniciadas na década de 1990, já denunciava a forte influência do multiculturalismo sob essas reformas, explicando:

Ao mesmo tempo, a teorização sobre o currículo escolar mostrou-se um campo muito propício à disseminação de estudos de autores internacionais nas vertentes neomarxistas, pós-estruturalistas, multiculturalistas, pós-colonialistas, pós-críticas, dentre outras. Formava-se, assim, o terreno propício para o fenômeno denominado por Duarte (2008) como "o esfacelamento do currículo realizado pelas pedagogias relativistas". O discurso da multiculturalidade situa-se, portanto, nesse processo de disseminação de uma visão de mundo que, aparentemente, defende a inclusão social, a democratização, o respeito à diversidade cultural etc., mas que, na realidade, tem como função principal a legitimação ideológica do capitalismo contemporâneo (MALANCHEN, 2014, p.18). 
Tal proposta vem sendo adensada por proposições pedagógicas signatárias da ideia de que as novas tecnologias alteraram em definitivo a base estruturante da sociedade do trabalho para o conhecimento, as denominadas pedagogias do 'aprender a aprender' disseminadas, principalmente, pelo Relatório Jacques Delors Educação um tesouro a descobrir, que defende:

[...] são mais desejáveis as aprendizagens que o indivíduo realiza por si mesmo, nas quais está ausente a transmissão, por outros indivíduos, de conhecimentos e experiências. [...] é mais importante o aluno desenvolver um método de aquisição, elaboração, descoberta, construção de conhecimentos, que esse aluno aprender os conhecimentos que foram descobertos e elaborados por outras pessoas. [...] a atividade do aluno, para ser verdadeiramente educativa, deve ser impulsionada e dirigida pelos interesses e necessidades da própria criança. [...] além do aluno buscar por si mesmo o conhecimento e nesse processo construir seu método de conhecer, é preciso também que o motor desse processo seja uma necessidade inerente à própria atividade do aluno [...] a educação deve preparar os indivíduos para acompanharem a sociedade em acelerado processo de mudança (DUARTE, 2003, pp.7-10).

Nesta perspectiva, o método de construção do conhecimento é mais importante que o conhecimento já produzido socialmente, assim, estabelece uma hierarquia valorativa, na qual aprender sozinho situa-se em um nível mais elevado que o da aprendizagem resultante da transmissão de conhecimentos por alguém. A defesa do relativismo cultural vincula-se à negação da possibilidade de apreensão do real, do conhecimento objetivo e da existência de uma cultura universal, o que se relaciona à crítica pós-moderna ao racionalismo moderno.

Com base no que foi mencionado, podemos afirmar que o patamar minimalista de formação almejado pela DPS foi incorporado pela BNCC. Porém, a possibilidade aberta pelo documento vai além, já que possibilita o aprofundamento das políticas de privatização, divisão técnica do trabalho e responsabilização. Na BNCC, "[...] cada objetivo de aprendizagem e desenvolvimento é identificado por um código alfanumérico" (BRASIL, 2017, p. 26), o que torna possível um rastreamento mais amplo e preciso dos resultados (FREITAS, 2017), estabelecendo novas bases para 0 aprofundamento das políticas de responsabilização no país. Além disso, a privatização e a divisão técnica do trabalho na escola também podem ser impactadas. A padronização em escala nacional dos objetivos de aprendizagem deve aumentar a pressão para que as redes públicas adotem os Sistemas Privados de Ensino, pois a BNCC, ao permitir que um mesmo sistema seja adotado em diferentes regiões do 
país, estimula grandes empresas de produção de material de didático padronizado a se estabelecerem no país, sustentadas na ideia de que suas mercadorias, alinhadas à BNCC, promovem aumento do desempenho dos alunos.

\section{Considerações finais}

A BNCC encontra-se no bojo das contrarreformas, que expressam e consolidam o projeto da classe dominante brasileira em sua marca antinacional, antipovo, antieducação pública, que condena gerações ao trabalho simples e nega os fundamentos das ciências que permitem aos jovens entenderem e dominarem como funciona o mundo das coisas e a sociedade (MOTTA e FRIGOTTO, 2017).

A institucionalização de um currículo minimalista é necessária ao rebaixamento da formação básica das camadas populares. Em suma, os reais objetivos do projeto formativo do empresariado são: i) a escola pública para integração, convivência, apaziguamento, adaptação e empregabilidade precária para os trabalhadores; ii) avanço no mercado de materiais didáticos e exploração de um mercado inteiramente novo de formação docente; consultoria; sistemas informatizados; iii) o controle do trabalho educativo. Além disto, na política do MEC, a BNCC deverá reposicionar todo o sistema de avaliação em larga escala do país (ANA; Prova Brasil; ENEM), vide Decreto 9.432/18 (BRASIL, 2018), que Regulamenta a Política Nacional de Avaliação e Exames da Educação Básica. Sem contar o avanço das "parcerias público-privadas" como estratégia de privatização da Educação Básica pela venda de pacotes e determinação do conteúdo e dos métodos de ensino por institutos privados ou organizações sociais, supostamente neutras.

Diante disto, urge o desenvolvimento e a prática de proposições formativas contra-hegemônicas, centradas na elevação do padrão cultural dos trabalhadores por meio da transmissão do conhecimento científico, filosófico e artístico em suas formas mais desenvolvidas. Proposições que pautem uma formação que se coloque "[...] a serviço do desvelamento da prática social, apto a promover o questionamento da realidade fetichizada e alienada que se impõe aos indivíduos" (MARTINS, 2010, p.20). A crise estrutural do capital nos coloca a tarefa enquanto classe trabalhadora, no âmbito educacional, de pensar e propor uma educação para a transição, ou seja, uma educação concatenada com a necessária passagem para um modo de produzir a 
existência que rompa com a propriedade privada dos meios de produção - o socialismo ${ }^{6}$ como transição para o comunismo.

Neste sentido, identificamos nas elaborações da pedagogia histórico-crítica elementos fundamentais não apenas para tecer a crítica ao projeto educacional burguês, mas, sobretudo, para fazer proposições que indicam possibilidades para enfrentá-lo nas condições históricas atuais. Afinal,

[...] a teoria curricular sob à luz da Pedagogia Histórico-Crítica, se diferencia das teorias pedagógicas hegemônicas atuais porque defende a superação da educação escolar em suas formas burguesas, sem negar a importância da transmissão, por esta, dos conhecimentos historicamente produzidos nesta mesma sociedade, para a formação do homem omnilateral (MALANCHEN, 2014, p.08).

Os conhecimentos científicos, filosóficos e artísticos se articulam em função do objetivo propriamente pedagógico (desenvolvimento humano), que significa a transformação qualitativa de seu modo de inserção na prática social. Não podemos perder de vista a noção do todo, em especial, a unidade conteúdo-forma, pois alterar o conteúdo que é ensinado nas escolas, avançando na socialização do saber sistematizado, perpassa pela alteração da forma de organização escolar. Assim como é impossível pensar a alteração da organização escolar sem que haja a alteração do conteúdo que é tratado na escola (GAMA, 2015).

Além disso, se é verdade que devemos buscar "[...] na cultura produzida pelos seres humanos, o que há de mais rico, o que existe de mais desenvolvido para transmitir às novas gerações" (MALANCHEN, 2014, p.124), isto implicando na

\footnotetext{
${ }^{6} \mathrm{O}$ socialismo é entendido como uma necessidade concreta de transição para o comunismo, que tem por base a tomada dos meios de produção pelos trabalhadores, a superação da subsunção do trabalho ao capital. O comunismo para Marx e Engels, não é um estado de coisas que deve ser instaurado, um ideal para o qual a realidade deverá se direcionar, mas sim o movimento real que supera o estado de coisas atual. As condições desse movimento devem ser julgadas segundo a própria realidade efetiva e resultam dos pressupostos atualmente existentes. Sobre o processo de degeneração do modo capitalista de produzir e reproduzir a existência, e a necessidade de transição para o modo de produção socialista/comunista Engels explica: "[...] as formas capitalistas de produção e de troca vão convertendo-se em entraves cada vez mais insuportáveis para a própria produção; que o regime de distribuição, necessariamente condicionado por essas formas, engendrou, por sua vez, uma situação de classe cada dia mais insuportável e mais aguda, um antagonismo sempre mais profundo entre alguns capitalistas, cada vez em menor número, porém cada vez mais ricos e uma massa de operários assalariados, cada vez mais numerosa e, em geral, também mais desfavorecida e mal retribuída; e finalmente, demonstra que a massa das forças produtivas que engendra o regime capitalista de produção e que este regime não consegue mais governar, está esperando tome posse das próprias forças produtivas uma sociedade organizada sob um regime de cooperação, baseada num plano harmônico destinado a garantir a todos os indivíduos da sociedade, em proporção cada vez maior, os meios necessários de vida e os recursos para o livre desenvolvimento de sua capacidade" (ENGELS, 1979, p.130).
} 
socialização do saber sistematizado pela escola; também é verdade que precisamos recuperar o que há de mais desenvolvido do ponto de vista das relações humanas, suas formas de organização, garantindo seu acesso às novas gerações. Afinal, a formação do homem novo, da consciência política precisa ser desenvolvida também através do cultivo de valores e atitudes comunistas para que a escola passe de correia de transmissão da ideologia burguesa, reproduzindo as estruturas existentes (SNYDERS, 2005), para terreno de luta onde florescem as forças do progresso, a possibilidade de libertação que ameaça a ordem estabelecida (GAMA, 2015).

\section{Referências:}

ADRIÃO, T. Dimensões e formas da privatização da educação no Brasil: caracterização a partir do mapeamento de produções nacionais e internacionais. Currículo sem Fronteiras, v. 18, n. 1, p. 8-28, jan./abr. 2018.

AFONSO, A. J. Para uma conceitualização alternativa de accountability em educação. Educação e Sociedade, Campinas; v. 33, n. 119, p. 471-484, abr./jun.2012.

BRASIL. Plano Diretor da Reforma do Aparelho de Estado. Define objetivos e estabelece diretrizes para a reforma da administração pública brasileira. Brasília, DF, 1995.

. Texto Anexo - Base Nacional Comum Curricular - Educação Infantil e Ensino Fundamental. In: BRASIL. Ministério da Educação. Conselho Nacional de Educação. Parecer CNE/CP no 15/2017. Brasília, DF, 2017.

Decreto no 9432/2018. Regulamenta a Política nacional de Avaliação e Exames da Educação Básica. Brasília, DF, 2018.

BECSKEHÁZY, L.; LOUZANO, P. Sala de aula estruturada: o impacto do uso de sistemas de ensino nos resultados da Prova Brasil - um estudo quantitativo no estado de São Paulo. São Paulo: Fundação Lemann, [201-].

DUARTE, N. Sociedade do conhecimento ou sociedade das ilusões?: quatro ensaios crítico-dialéticos em filosofia da educação. Campinas, SP: Autores Associados, 2003.

ENGELS, F. Anti-Dühring: filosofia, economia política, socialismo. 2. ed. Rio de Janeiro: Paz e Terra, 1979.

FUNDAÇÃO ITAÚ SOCIAL. Guia de tutoria pedagógica. [201-]. Disponível em: $<$ http://fundacao-itau-social-producao.s3.amazonaws.com/files/s3fs-

public/biblioteca/documentos/tutoriapedagogica.pdf?V24jDF.33d88JXFd1WEef_RdX bQUSj4e>. Acesso em: 15 fev. 2016. 
Educação para o desenvolvimento sustentável. 2013a. Disponível em: <http://www.fundacaoitausocial.Org.br/_arquivosestaticos/FIS/pdf/perfil2013.pdf>. Acesso em: 17 dez. 2014.

2013b.

Jovens urbanos: marcos conceituais e metodológicos. São Paulo: FIS,

Percursos da educação integral: em busca da qualidade e da equidade. São Paulo: CENPEC/Fundação Itaú Social, 2013c.

FUNDAÇÃO LEMANN. Apoio à Base nacional Comum Curricular: todos os alunos e alunas têm o direito a uma educação de qualidade. 2018. Disponível em: $<$ https://fundacaolemann.org.br/projetos/apoio-a-base-nacional-comum-curricular>. Acesso em: 26 de junho de 2018.

FREITAS, L. C. de. BNCC: como os objetivos serão rastreados?. 2017. Disponível em: <https://avaliacaoeducacional.com/2017/04/07/bncc-como-os-objetivos-seraorastreados/>. Acesso em: 16 de novembro de 2018.

GALL, N.; GUEDES, P. M. A reforma educacional de Nova York. Possibilidades para o Brasil. São Paulo: Fundação Itaú Social, 2012.

GAMA, C. N. Princípios curriculares à luz da Pedagogia histórico-crítica: as contribuições da obra de Dermeval Saviani. Tese (Doutorado em Educação) Faculdade de Educação, Universidade Federal da Bahia, Salvador, 2015.

INSTITUTO ETHOS. O que as empresas podem fazer pela educação. São Paulo: CENPEC/Instituto Ethos, 1999.

LOUZANO, P. et. al. Sistemas Estruturados de Ensino e Redes Municipais do Estado de São Paulo. São Paulo: Fundação Lemann, 2008.

MALANCHEN, J. A pedagogia histórico-crítica e o currículo: para além do multiculturalismo das políticas curriculares nacionais. Tese (Doutorado em Educação). Araraquara (SP): Universidade Estadual Paulista, 2014.

MARSIGLIA, A. C. G. et. al. A base nacional comum curricular: um novo episódio de esvaziamento da escola no Brasil. Germinal: Marxismo e Educação em Debate, Salvador, v. 9, n. 1, p. 107-121, abr. 2017.

MARSIGLIA, A. C. G.; MACHADO, V. de O.; PINA, L. D.. O golpe de estado e a base nacional comum curricular: um novo episódio do esvaziamento curricular das escolas públicas no Brasil. In: SARTÓRIO, L. A. V.; LINO, L. A.; SOUZA, N. M. P. (Org.s). Política educacional e dilemas do ensino em tempo de crise: juventude, currículo, reformas do ensino e formação de professores. 1ed.São Paulo: Editora Livraria da Física, 2018, v., p. 53-87.

MARTINS, A. S.. A direita para o social: a educação da sociabilidade no Brasil contemporâneo. Juiz de Fora: Editora da UFJF, 2009. 
MARTINS, L. M. O desenvolvimento do psiquismo e a educação escolar: contribuições à luz da psicologia histórico-cultural e da pedagogia histórico-crítica. Campinas, SP: Autores Associados, 2013.

O legado do século XX para a formação de professores. In: MARTINS, L. M.; DUARTE, N. (orgs.). Formação de professores: limites contemporâneos e alternativas necessárias. São Paulo: Cultura Acadêmica, 2010.

MELLO, G. N. de. Como um bom sistema de ensino pode melhorar o aprendizado. Entrevista concedida à Camila Pereira. Sala de aula estruturada - 0 impacto do uso dos sistemas de ensino nos resultados da Prova Brasil - um estudo qualitativo no Estado de São Paulo. São Paulo: Seminário da Fundação Lemann, 04 jul. 2010. Disponível em: <http://www.youtube.com/watch?v=5QEk5-cPldQ>. Acesso em: 24 out. 2014.

MOTTA, V. C. da; FRIGOTTO, G. Por que a urgência da reforma do ensino médio? Medida Provisória no 746/2016 (LEI ํo 13.415/2017). Educação e Sociedade, Campinas, v. 38, №. 139, p.355-372, abr.-jun., 2017.

PINA, L. D. "Responsabilidade social" e educação escolar: o projeto de educação básica da "direita para o social" e suas repercussões na política educacional do Brasil contemporâneo. 2016. Tese (Doutorado em Educação) - Faculdade de Educação, Universidade Federal de Juiz de Fora, Juiz de Fora, 2016.

PONTUAL, T. C. Remuneração por mérito: desafio para a educação. São Paulo: Fundação Lemann, 2008.

RAMOS, M. N. Pedagogia das competências: autonomia ou adaptação? São Paulo: Cortez, 2001.

RAVITCH, D. Vida e morte do grande sistema escolar americano: como os testes padronizados de mercado ameaçam a educação. Porto Alegre: Sulina, 2011.

SAVIANI, D. Escola e Democracia: teorias da educação, curvatura da vara, onze teses sobre a educação política. 38. ed. Campinas: Autores Associados, 2006.

Associados, 2011.

História das ideias pedagógicas no Brasil. 3. ed. Campinas: Autores

SHIROMA, E. O.; EVANGELISTA, O. Avaliação e responsabilização pelos resultados: atualizações nas formas de gestão de professores. Perspectiva, Florianópolis, v. 29, n. 1, 127-160, jan./jun. 2011.

SNYDERS, G. Escola, classe e luta de classes. São Paulo: Centauro, 2005.

TODOS PELA EDUCAÇÃO. As 5 Bandeiras. 2018. Disponível em: $<$ https://www.todospelaeducacao.org.br/indicadores-da-educacao/5-bandeiras>. Acesso em: 26 de junho de 2018. 